\title{
A fé e o direito: a exegese canônica
}

\section{Faith and law: the canonical exegesis}

\author{
Mário Arthur de Souza Fontes ${ }^{1}$ \\ Marcos Machado ${ }^{2}$
}

Artigo

Original

Original

Paper

\begin{abstract}
Palavras-chave:
Resumo

Exegese

Já no seu trigésimo ano o projeto da exegese canônica no Brasil, é uma realidade e cuja, a intenção consiste em ler os textos individuais, no con-

Escrituras

Teologia junto da única Escritura, onde todos os textos particulares acendem a uma nova luz, luz esta, que desde a constituição do Concílio Vaticano II, perdura sobre a Revelação, um princípio fundamental da exegese teológica; e, aquele que procura entender a Escritura dentro do contexto no qual foi escrita, terá de considerar o conteúdo e a unidade de toda a Escritura; por outro lado, a tradição viva de toda a igreja e a analogia da fé e o direito

Igreja

Fé desta proteção, antes das releituras empreendidas onde gerou algumas alterações e esta cisão entre o Jesus histórico e o Cristo da fé, tornou-se cada

Direito vez mais profunda, afastando-se ambos rapidamente um do outro; mas o que é que pode significar a fé em Jesus Cristo "o filho do Deus vivo" se o homem Jesus, foi totalmente diferente daquele que os evangelistas o representam e daquele que a igreja, partindo dos evangelhos, anuncia! Portanto este artigo por um lado indica o sentido do método histórico-crítico com a Fé e por outro a visão do Direito com a Boa-fé Canônica.
\end{abstract}

\begin{abstract}
In its third year the project of the canonical exegesis in Brazil is a reality which aims to read the individual texts in the Scripture, which all the private texts come on a new light. The one that since the constitution of the Vatican council II beholds a Revelation, the fundamental principals of the theological exegesis which the person who tries to interpret the Scripture in the context which was written will have to consider the content and the unit of the whole Scripture. On the other hand the alive tradition of the whole church and the analogy of faith and the law to this protection, before the reading that generated some alterations and the division between the historical Jesus and the Christ of faith, became deeper, taking them apart. But what can the faith in Jesus Christ "the son of God alive" mean if the man Jesus was totally different from what the evangelists represented him and from what the church, starting from the gospels, announce! So this article shows the sense of the historical-critical method of Faith and on the other hand the sense of Law and the canonical good-faith.
\end{abstract}

Key words:

Exegesis

Scriptures

Theology

Church

Faith

Law

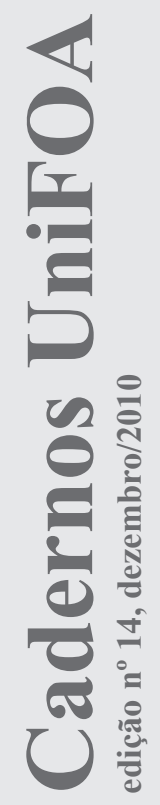




$\begin{array}{ll}\text { Palabras clave: } & \text { Resumen: } \\ \text { Exegese } & \begin{array}{l}\text { En su trigésimo año, la exégesis canónica del proyecto en Brasil, que } \\ \text { es una realidad y la intención es leer los textos individuales en toda la } \\ \text { Escritura único, donde todos los textos privado iluminar una nueva luz, } \\ \text { la luz de lo anterior, que desde la creación del Concilio Vaticano II, sigue } \\ \text { en el Apocalipsis, un principio fundamental de la exégesis teológica, y } \\ \text { uno que trata de comprender las Escrituras en el contexto en que fue } \\ \text { escrito, usted tiene que considerar el contenido y la unidad de toda la } \\ \text { Escritura, para Por otra parte, la tradición viva en toda la Iglesia y } \\ \text { la analogía de la fe y el derecho de protección, antes de emprenderse } \\ \text { la releituras que ha generado algunos cambios y esta división entre el } \\ \text { Jesús histórico y Cristo la fe, se ha convertido cada vez más profunda, } \\ \text { distanciando rápidamente tanto el uno del otro, pero lo que puede } \\ \text { significar la fe en Jesus Cristo el Hijo de Dios vivo "si el hombre Jesús, } \\ \text { era totalmente diferente del que representan a los evangelistas y que } \\ \text { la iglesia, comenzando con los evangelios, anuncia ! Por lo tanto, este } \\ \text { artículo, por un lado, indica la dirección del método histórico-critico con } \\ \text { la Fe y la otra la visión de la ley con la buena fe Canônica. }\end{array}\end{array}$

\section{Introdução}

A exegese canônica, ou seja, ler os textos particulares da Bíblia na sua totalidade é uma dimensão essencial da explicação, que não está em contradição com o método histórico-crítico, mas que de algum modo orgânico o desenvolve e lhe permite tornar-se autêntica teologia.

$\mathrm{O}$ artigo irá evidenciar mais dois aspectos da exegese teológica: a explicação histórico-crítico do tema e procurará indagar o sentido no seu espaço e no seu momento temporal. Isto será muito interessante e importante, pois independentemente da certeza, que na verdade, é apenas relativa de tais reconstruções, mas vital é ter presente, que cada palavra humana, pelo seu próprio peso, já transporta em si mais do que aquilo de que se pode momentaneamente estar conscientemente escrevendo. Temos como definição:

Exegese é a interpretação profunda de um texto bíblico, jurídico ou literário. A exegese como todo saber, tem práticas implícitas e intuitivas. A tarefa da exegese dos textos sagrados da Bíblia tem uma prioridade e anterioridade em relação a outros textos. Isto é, os textos sagrados são os primeiros dos quais se ocuparam os exegetas na tarefa de inter- pretar e dar seu significado. A palavra exegese deriva do grego exegeomai, exegesis; ex tem o sentido de ex-trair, ex-ternar, ex-teriorizar, ex-por; quer dizer, no caso, conduzir, guiar. ${ }^{1}$

Essa será a força interior da palavra, que transcende o seu momento e alcança a sua validade, a partir das palavras que foram amadurecidas pelo processo da história de fé. Durante a pesquisa e as análises ao tema, viu-se que não se consegue falar a partir de nós mesmos. Somente fala-se a partir de uma história comum, que nos transporta e na qual está presente o tempo todo em surdina, possibilitando um futuro pelo vasto caminhar. Portanto, o processo das leituras continuadas e do desenvolvimento das palavras não teria sido possível, se não estivessem presentes nas próprias palavras, em até íntimos raciocínios. Nesta pesquisa para o artigo, podemos por assim dizer, pressentir mesmo que historicamente, o que significa inspiração: Há dimensões da palavra às quais a antiga doutrina dos quatro sentidos da Escritura, aludiu no seu núcleo de um modo inteiramente próprio, pois são sentidos individuais, precisamente na dimensão da palavra, que transcende o instante em uma influencia mística.

Tem-se que a Escritura cresceu a partir da cisão do sujeito vivo que é o povo de Deus 
peregrino e que habita nesses, o Jesus histórico e o Cristo da fé. "O Jesus histórico é aquele personagem reconstruído pelas informações que chegaram até nós através de vários documentos históricos"2. Sempre os livros das Escrituras se referem, a três sujeitos que atuam uns com os outros e que pertencem ao sujeito do povo de Deus. A relação com o sujeito "Povo de Deus" é importante e vital para a Escritura, pois é a medida que tem em Deus a sua origem e a força que dirige esse povo, mas por outro lado, a Escritura vive só e precisamente neste povo e se supera assim: a partir da palavra encarnada, que precisamente se torna o povo de Deus. E esses: o povo de Deus, a Igreja e as Escrituras, são o sujeito vivo, pois as palavras bíblicas, estão sempre presentes; em última instância e a partir de Cristo: se deixe ordenar, se conduzir e ou se dirigir por ele, pois ai esta a representação de Jesus o que significa, a confiança nos Evangelhos, na posição do Concílio e a moderna exegese nos diz pelos gêneros literários, uma intenção narrativa sem rodeios, mas em contexto vivo. $\mathrm{O}$ artigo tenta representar o Jesus dos Evangelhos, como o Jesus real, como o Jesus histórico no sentido autêntico. Há que se ter o sentimento dessa figura "o Jesus dos Evangelhos" racional e manifestamente histórica. É assim o históricocrítico com a fé e a visão do Direito, com a boa-fé Canônica.

Quando se deu algo de extraordinário, na figuração e nas palavras de Jesus, radicalmente ultrapassam a média de todas as esperanças e expectativas, que se esclareceu na sua crucificação e também na sua ação. Pois cerca de vinte anos depois da morte de Jesus, já começa-se a encontrar no grande hino cristológico na carta aos filipenses (Fl. 2, 6-11) uma desenvolvida proclamação a Jesus, o igualando a Deus, fenômeno esse que se desfez de si mesmo, pois se fez homem, se humilhou e foi humilhado até a morte na cruz e agora, lhe é devida uma veneração cósmica, esta foi a indulgente adoração que Deus o Pai, anunciou ao profeta Isaías (Is. $43,23)$ para Jesus o seu filho.

\section{Das escrituras a esperança e o mistério de Jesus}

A descida do Espírito Santo sobre Jesus, que dá-se no batismo, institui formalmente o seu mistério. Por isso o clero, estudiosos, exegeta católico de várias línguas o pesquisam e o estudam.

No livro do Deuteronômio encontra-se uma promessa, que sendo inteiramente diferente da esperança messiânica de outros livros do antigo testamento é, no entanto de significado decisivo para a compreensão da figura de Jesus. Não foi prometido nem um Rei a Israel ou ao mundo, nem um novo Davi, mas um novo Moisés e esse indicado como profeta, de natureza diferente, uma particularidade da fé em Deus que foi oferecida a Israel, porque em todos os tempos, o homem não se interrogou apenas a respeito do seu final, quer ter esperança em maior escala do que a obscuridade das suas origens, ocupar-se por tudo o homem, com a reserva do futuro do qual ele se aproxima, sempre tentando rasgar a cortina e novamente, com a esperança de saber o que acontecerá, para escapar do mal e para ir ao encontro da salvação. As religiões não estão apenas ordenadas para o futuro, elas são importantes, precisamente, porque sabem mediar sobre o que há de vir e podendo assim indicar ao homem o caminho que deve tomar, para não fracassar, no seu intuito de salvar-se, como as prescrições nas Escrituras. O livro do Deuteronômio refere-se a diversas formas de abertura para o futuro, tanto que em (Dt. 18, 9-12) está: “.... porque o Senhor, teu Deus, abomina aqueles que se dão a essas práticas...”’, mas nas Escrituras temos uma controvérsia:

Saul antes da batalha contra os filisteus, tinha pela frente, um silêncio sepulcral por parte de Deus, era insuportável, não se contendo, sai a cavalo e vai encontrase com uma vidente em Endor, pedindo que lhe chamasse o espírito de Samuel, a fim de lhe abrir a visão, sobre o futuro da batalha. ${ }^{4}$ 
Temos em (1Sm 28), tem-se a polêmica: "Se o Senhor não fala, então um outro deve retirar o véu do amanhã", na procura da esperança, assim está nas Escrituras, o homem encontra os Mistérios de Jesus.

No Capítulo 18 em Deuteronômio, também estigmatiza, todas as formas de capturar o futuro, como abominação aos olhos de Deus, contrapondo a esta advinhação um outro caminho de Israel-caminho da fé e isto na forma de uma promessa: "O Senhor, teu Deus, te suscitará dentre os teus irmãos um profeta como eu: é a ele que deverá ouvir" (Dt 18,15) ${ }^{5}$. Em primeiro passar d'olhos, parece que é um pequeno anúncio da "Instituição" do profetismo em Israel e ao Profeta fica a atribuição da explicação do presente e do futuro, como crítica aos falsos profetas, que repetidamente se encontra nos livros proféticos, que com grande severidade, mostra o perigo que há de os profetas assumirem o papel de advinhos, o que seria uma de suas missões, exatamente o contrário: impedir, assim está nas Escrituras. Ainda em Deuteronômio retorna a promessa e dá-lhe uma surpreente virada, que vai muito além da instituição do profetismo, assim oferecendo a figura do profeta o seu autentico sentido: "Não se levantou mais em Israel profeta comparável a Moisés, com quem o Senhor conversava face a face" $"$ (Dt 34,10)

No livro de Êxodo cita que Moisés fez um pedido a Deus, Qual seja: "Mostrai-me vossa glória"7 (Ex 33,18), mas o pedido não é atendido. E Deus falou: "Mas, ajuntou o Senhor, não poderás ver a minha face, pois o homem não me poderia ver e continuar a viver." " 33,20) mas, em sua infinita misericórdia com aqueles que lhe são fieis, Deus cobre-o durante a sua passagem com a sua própria mão, e quando a retira diz: "Retirarei depois a mão, e me verás por detrás. Quanto à minha face, ela não pode ser vista." (Ex 33,23). Estes mistérios desempenharam um papel essencial na história da mística cristã e Judaica e a partir dele, procurou distinguir-se até onde pode ir o contato com Deus nesta vida e por onde podem passar os limites da visão mística.

Mas uma coisa importante se torna evidente nos estudos e análises feitas para este artigo: na comunhão filial de Jesus com o Pai a alma humana de Jesus era envolvida no ato da oração, "Quem vê Jesus vê o Pai"10 (Jô 14,9). O discípulo que caminha com Jesus, será assim introduzido com ele na comunhão com Deus e isto é que é autenticamente redentor, ou seja, a superação dos limites da humanidade, que já está desde a criação, tem na imagem de Deus, conforme as Escrituras, a esperança e a possibilidade de um melhor futuro. "Mistérios do Cordeiro de Deus".

\section{O Messias - Cristo e o direito de unção}

A descida do Espírito Santo sobre Jesus, no seu batismo, institui formalmente o seu Mistério. Por isso nestes estudos e análises vimos uma analogia com o "Direito da Unção", com a qual Reis, Ministros e os Sacerdotes, eram elevados aos mistérios em Israel. A morfologia da palavra "Messias-Cristo", que significa o ungido, isto porque a Unção era considerada na Antiga Aliança, o sinal visível da dotação com os talentos do Ministério, com o Espírito de Deus. Em (Is 11,2), deixa-nos em conseqüência a "esperança" a respeito de um verdadeiro ungido, cuja "Unção" consiste precisamente em sobre ele descer o Espírito do Senhor, o Espírito da sabedoria e da inteligência, o Espírito do conselho e da força, o Espírito do conhecimento e do temor de Deus. Segundo o relato de Lucas, Jesus apresentou-se a si mesmo e a sua missão na Sinagoga de Nazaré, com uma citação análoga a de Isaias: "O Espírito do Senhor está sobre mim, porque me ungiu"11 (Lc 4,18) e "O espírito do Senhor repousa sobre mim, porque o Senhor consagrou-me pela unção"12 (Is 61,1); por isso concluirmos que a verdadeira "Unção" é a do batismo, em que 
perante o povo de Jesus recebeu a Dignidade Real e a Dignidade Sacerdotal. É neste ponto, que começa a inserção de um "ato jurídico", a relação com o Direito Legado e foi neste batismo, que Jesus atém legalmente a "Unção", para falar por Deus e decidir por Ele mesmo.

BÍBLICAMENTE: Unção vem do substantivo grego, chrisma; daí, vem o verbo chrío, ungir; e o adjetivo christós, que significa "ungido". No hebraico, o termo ungido é Messias, aplicado a Cristo. A unção, na Bíblia, pode ser entendida de modo espiritual e literal, com a aplicação do azeite ou óleo sobre alguém ou sobre algum objeto. ${ }^{13}$

A partir de então, Ele está subordinado a missão de conhecer os perigos enfrentados pelos homens, porque só assim pode o homem caído ser levantado, Jesus deve adentrar no drama da existência humana, atravessá-la, ir até o fundo, para encontrar a ovelha perdida, colocá-la nos ombros e levá-la para casa. Jesus por sua missão, deve assemelhar-se em tudo aos seus irmãos, para que seja o Sumo Sacerdote misericordioso e fiel nos serviços de Deus, para expiar os pecados do povo, até porque ele mesmo foi tentado e porque pode socorrer os que são tentados $(\mathrm{Hb} 2,17 \mathrm{~s})^{14} \mathrm{e}(\mathrm{Hb}$ $4,15)^{15}$. Assim deve restaurar aquela paz que Isaias anunciou, para os tempos do messias: "Então o lobo será hóspede do cordeiro, a pantera se deitará ao pé do cabrito..." ${ }^{\prime 16}$ (Is 11,6 ), onde o pecado é vencido, onde a harmonia do homem com Deus é restaurada e segue-se a reconciliação da natureza, a criação dilacerada transforma-se em lugar de paz e "Por isso, a criação aguarda ansiosamente a manifestação dos filhos de Deus"17 (Rm 8,19).

Por ter recebido a Unção, na espetacular visão Jurídica nos tempos de hoje, onde um herdeiro é dono, fica claro que Jesus poderia ter respondido com a expressão do Direito Legado e a altura quando era argüido: "Se és Filho de Deus, ordena que estas pedras se transformem em pães"18 (Mt 4,3) e outra foi em calvário pelos escarnecedores junto à cruz: "Se és filho de Deus, então desce da cruz e salva-te"19 (Mt 24,40). O livro da sabedoria, já havia previsto esta situação: "Se o justo é filho de Deus, Deus o defenderá..." ${ }^{20}$ (Sb 2,18).

Tal como em Mateus, também em Marcos a história se confirma: “...e os anjos aproximaram-se dele para servi-lo" ${ }^{21}(\mathrm{Mt} 4,11)$ e "E os anjos o serviram"22 (Mc 1,13). Ainda em nossas pesquisas, também se cumpre em $(\mathrm{S} 1 \text { 91,14) })^{23}$ : “Os anjos servem-no, Ele provou ser o filho de Deus e por isso sobre ele, como novo Jacó, o pai de Israel tornado universal, está em céu aberto"24 (Gn 28,12).

\section{O direito e a boa fé canônica}

Quando Joseph Ratzinger foi eleito papa há pouco tempo atrás, escolhendo o nome de Bento XVI, para seu pontificado em uma dupla homenagem a São Bento de Núrsia (480-547), fundador da Ordem Beneditina da idade média e considerado o padroeiro da Europa, por causa do papel dos Mosteiros Beneditinos na resistência às invasões bárbaras naquela época e ao Papa Bento XV (1854-1922), responsável por uma das mais importantes reformas administrativas da Igreja Católica e de inúmeras tentativas fracassadas de trazer paz a Europa durante a primeira grande guerra. As duas homenagens prestadas por Ratzinger apontam em uma mesma direção, qual seja: os dois desafios mais caros que o cristianismo enfrentou e ainda enfrenta, desde que vindo do Oriente e chegando ao continente Europeu: "Manter a paz entre os seus povos e construir uma unidade ao redor dos valores cristãos", por isso a preocupação central de Bento XVI, em indicar o sentido que pretende dar ao seu pontificado, que está muito restrito e a esse duplo desafio, também há lógico, razões para vislum-

\footnotetext{
${ }^{13}$ LIMA, Elinaldo Renovato. As Bases Bíblicas da Unção. Disponível em: < http://www.assembleiadedeus-rn.org.br/familia/port/estudos01.htm> Acesso em: 13 abr. 2010.

${ }^{14}$ BÍBLIA SAGRADA, op. cit., p. 1528.

${ }^{15}$ Ibid., p. 1529

${ }^{16}$ Ibid., p. 954.

${ }^{17}$ Ibid., p. 1457.

${ }^{18}$ BÍBLIA SAGRADA, op. cit., p. 1287.

${ }^{19}$ Ibid., p. 1315.

${ }^{20}$ Ibid., p. 837.

${ }^{21}$ Ibid., p. 1287.

${ }^{22}$ Ibid., p. 1322

${ }^{23}$ Ibid., p. 731.
}

${ }^{24}$ Ibid., p. 75. 
brar um pontificado tão burocrático quanto ao conclave que o elegeu, já que a "Unificação Secular da Europa" se parece dar, em passos, bem largos e muito maior que os da construção de uma Unidade Religiosa Mundial. Em verdade deixa-nos a pesquisa feita para esse artigo, que esse Papa, entretanto, não é somente um intelectual da Unidade Européia, ele é também e, principalmente, um intelectual do Direito e da Boa Fé Canônica. Seu antecessor Bento XV, também era um intelectual do Direito, era o sucessor de Pio $X$, um Papa não muito diferente de João Paulo II, em carisma e ênfase da missão evangélica do papado e nos deixou o "Codex Iuris Canonici" (Código do Direito Canônico), promulgado em 1917, tem algumas diferenças de Bento XVI, no entanto, preocupou-se com as leis em tempos de guerra e extrema incerteza jurídica no plano secular. Tentou, sem nunca conseguir, colocar o vaticano nas principais mesas de negociações, para o fim da guerra. Bento XV fracassou no terreno do Direito Internacional, então se voltou a partir de 1918, ao Direito Administrativo da Instituição que comandava como Papa, logicamente, ainda é precoce tentar vislumbrar qual a marca que o Papa Bento XVI deixará na Igreja Católica, mas na sua atuação como Prefeito da Congregação para a Doutrina da Fé, cargo que ocupou até assumir o papado, há indícios que esse intelectual do Direito buscará colar sua imagem pastoral à de seu antecessor e procurará dar maior visibilidade e penetração aos valores morais e éticos do tipo de cristianismo que pratica. Nesse sentido e em muito pouco tempo, já conquistou espaço em debates públicos internacionais, que Bento XV jamais conseguiu, ademais antes mesmo de ser tornar Papa, o Cardeal Joseph Ratzinger, já era conhecido como um intelectual importante, astuto e visível da Doutrina Tomista do Direito Natural; particularmente, preocupado em realizar um ordenamento e uma atualização desta doutrina aos tempos e aos temas de hoje. Sempre muito solícito, seus estudos foram discutidos com respeito pelo mundo jurídico e em palestras, seminários, congressos e conferências. Em uma dessas ocasiões mais precisamente em novembro de 2002 na Itália, então o cardeal Ratzinger proferiu sobre o tema: "A Crise e o Direito" este tema foi tão bem aceito que a Faculdade de Direito da LUMSA, lhe ortogou o título de "Doctor Honoris Causae". Em outra ocasião o famoso filósofo e estudioso do Direito Jürgen Habermas, em uma conferência em Frankfurt, em outubro de 2003 intitulada "A Fé e o Saber Jurídico", deixou claro o seu posicionamento sobre a religião em encontro com o saber e como se auto definiu, "Sem ouvido musical para a religião" e concluindo sua intervenção defendendo a possibilidade da fé não contribuir para a constituição da consciência e da linguagem democrática dos consensos que legitimam o mundo dito liberal e as instituições jurídicas laicas. O mundo culturado Europeu esperava até uma reação violenta, por parte de Ratzinger, logicamente em palavras, mas o Cardeal, por sua vez, como foi dito anteriormente, de quem se esperava uma postura defensiva arraigada ao dogma da religião com uma apresentação até burocrática dos argumentos conservadores tradicionais acerca dos dilemas morais e polêmicos.

Certamente na opinião pública da atualidade e na opinião de um outro também famoso filósofo Basco, Fernández Veja, se comportou como um Ratzinger "Polemista Urbano" um pluralista, a ponto de incluir em sua fala sobre $o$ assunto, menções a antigos e também inimigos da Igreja nos embates teológicos, que dirigia, enquanto Prefeito da Congregação para a Doutrina da Fé, na ocasião foi alcunhado pelos seus debatedores como: "O Cardeal Advogado".

Agora é analisar com parcimônia e muita cautela, entretanto, esta aparente aproximação entre o "Filósofo Laico" e o "Teólogo Advogado" cristão na sua essência, afinal o contexto desta passagem com os dois filósofos favorecia harmonias pouco dissonantes, ainda que polifônicas. O que se tornava repentinamente musica para os ouvidos de Habermas, pode acirrar uma discussão, bem como uma contribuição que a ética religiosa plurarista, pode dar ao debate democrático que não coincide necessariamente com aquilo que Ratzinger denomina ao final de sua intervenção de "O Contexto Intercultural da nossa atualidade e a essencial complementaridade entre a razão e a fé nesse contexto".

Portanto, o tema de Ratzinger de 2002 "A Crise e o Direito", ajuda a elucidar o enorme abismo que separa o pensamento do "Filósofo Laico" e do "Teólogo Advogado", 
bem como, os surpreendentes pontos de contato entre essas premissas, tanto que ele vê um ponto de tensão, entre a Soberania e os Direitos Humanos, que estão profundamente marcados, por uma contraposição milenar entre o caráter evangélico do modelo de virtude do "Novo Testamento" e o caráter jurídico do modelo de virtude do "Velho Testamento" e diferente do Apóstolo Paulo e de Lutero, Ratzinger não reconhece essa tensão, como real e como Mateus e São Thomaz de Aquino, estudioso antes dele ao tema, não creram também que isto seria possível de imaginar: "Primeiro a Lei" e "Depois a Fé"... .

\section{Verdade - tolerância - liberdade}

Para entender o ensinamento da complexidade da palavra fé e direito, dentro de mundo macro sociocultural e jurídico, devemos nos reportarmos a alguns conceitos básicos, entre eles - verdade; tolerância e liberdade - que são os degraus para a compreensão filosófica, cultural e jurídica, que ronda os dias atuais em busca das verdades; ou por outro lado, poderíamos chamar apenas de premissas.

É dentro desses dogmas, que o universo cresce de forma acelerada e desenfreada, numa velocidade além da luz, para tentar alcançar a compreensão dos eventos que ocorrem ao nosso redor. É nesse contexto que surge a necessidade de conhecer alguns conceitos básicos acerca dessas premissas, que são vertentes intrínsecas dentro da pesquisa.

Verdade significa o que é verdadeiro. Esta qualificação implica as de real e de imaginário, de realidade e de ficção, questões centrais tanto em antropologia cultural como na filosofia. A verdade é uma interpretação mental da realidade transmitida pelos sentidos, confirmada por outros seres humanos com cérebros normais e despidos de preconceitos (desejo de crer que algo seja verdade), e confirmada por equações matemáticas e lingüísticas formando um modelo capaz de prever acontecimentos futuros diante das mesmas coordenadas. O paradoxo da realidade ou verdade objeti- va afirma que a realidade ou a verdade, para serem provadas objetivamente, devem permanecer assentes após uma hipotética sucumbência de todos os seres humanos da face da terra. ${ }^{25}$

Conforme se depreende da leitura do texto citado acima, podemos afirmar com a devida prudência que a verdade não é absoluta, pois existem vários fatores que afetam de maneira direta e/ou indireta a construção desta - premissa - durante o processo de cognição do ser humano.

Esta afirmação é bastante peculiar, pois como o homem está num constante procedimento de aprendizagem universal, onde busca encontrar as respostas certa e que, primeiramente válidas, aproximam-se mais da tão almejada verdade; para saciar a sua, insaciável gula pelo saber, mas, por outro lado como ter a certeza absoluta de ter encontrado a verdadeira resposta para suas indagações?

Daí surge à necessidade de buscar um aprofundamento intelectual, no sentido de tentar alcançar as entranhas do conhecimento, e para que isso ocorra de maneira natural interna, precisamos compreender um pouco do sentido da palavra tolerância.

A tolerância, do latim tolerare (sustentar, suportar), é um termo que define o grau de aceitação diante de um elemento contrário a uma regra moral, cultural, civil ou física. Do ponto de vista da sociedade, a tolerância define a capacidade de uma pessoa ou grupo social de aceitar, noutra pessoa ou grupo social, uma atitude diferente das que são a norma no seu próprio grupo. Numa concepção moderna é também a atitude pessoal e comunitária face a valores diferentes daqueles adotados pelo grupo de pertença original. ${ }^{26}$

Agora diante de um precógnito dos conceitos de verdade e tolerância; podemos partir para tentar alcançar a premissa maior, que é no tocante a liberdade, e neste particular também beberemos da mesma fonte para construir um pensamento mais sólido, mas preliminar, a respeito do tema desta premissa maior. 
Em filosofia, "liberdade" designa, de uma maneira negativa, a ausência de submissão, de servidão e de determinação, isto é, ela qualifica a independência do ser humano. De maneira positiva, liberdade é a autonomia e a espontaneidade de um sujeito racional. Isto é, ela qualifica e constitui a condição dos comportamentos humanos voluntários. ${ }^{27}$

Depois desse preâmbulo, o qual nos possibilita ter uma compreensão imparcial e singular a respeito dessas "premissas", podemos tecer mais alguns comentários no tocante - fé e o direito - que é o foco principal desse nosso artigo científico, e nesse ponto crucial, nos reportamos alguns fragmentos de textos pinçados da obra escrita pelo próprio Joseph Ratzinger (Papa Bento XVI) - O cristianismo e as grandes religiões do mundo, traduzida pelo escritor Sivar Hoppner Ferreira, a qual possui um fundo filosófico e cultural, que serve de base para uma reflexão a acerca do mundo, demonstrado como agi e interagi essas "premissas".

Haverá contradição entre tolerância e fé na verdade revelada? Dito de outra forma: fé cristã e modernidade são compatíveis? Se a tolerância é um dos fundamentos da Idade Moderna, não será uma arrogância ultrapassada a afirmação de se ter conhecido a essência da verdade? Essa pretensão não deveria ser rejeitada, se quisermos quebrar a espiral de violência que perpassa a história das religiões? Essa pergunta se levanta, cada vez de forma mais dramática, nas religiões entre o cristianismo e o mundo de hoje. Cada vez mais se amplia a convicção de que a renúncia da fé cristã à sua pretensão à verdade é a condição básica para uma nova paz do mundo e para reconciliação do cristianismo com a modernidade. ${ }^{28}$

$\mathrm{Na}$ consciência dos homens de hoje, a liberdade aparece de longe como o bem máximo, ao quais todos os outros bens estão subordinados. Na linguagem do direito, quase sempre a liberdade da arte, a liberdade de expressões das próprias opiniões, tem a primazia sobre qualquer outro valor moral. Valores que concorrem com a liberdade, valores que possam tornar necessária sua limitação aparecem como grilhões, como "tabus"; ou seja; resíduos de proibições e temores arcaicos. ${ }^{29}$

Partindo dos pontos esculpidos no corpo dessas singelas linhas, e em especial neste subtítulo, verificamos que a verdade não é absoluta, pois como o próprio universo é dinâmico; o que significa dizer que todos os eventos e/ou seres vivos estão sempre em processo de aperfeiçoamento, e o ser humano não é diferente desta afirmação. Daí podemos concluir que nada é absoluto e sim relativo, pois o que hoje é real amanhã pode não ser tão real, como creditamos ontem.

A verdade é um eterno e constante processo de expansão de cognição, e para que isso ocorra de maneira natural e harmoniosa, precisamos ter uma dose de tolerância, dentro de cada um de nós, para aceitarmos as mudanças que vem com a liberdade de expressão humana, a qual possibilita o crescimento da própria humanidade.

\section{Conclusão}

O processo dos estudos e análises, para o fechamento deste artigo histórico, teológico e polêmico, que conduziu-nos a distinções refinadas e críticas das movimentações da pesquisa no esforço de produzir uma exegese de contexto científico, agradável, de fácil leitura e próprio ao tema.

Chegou-se a um momento apoteótico, onde os movimentos da fé, criação do homem, de sua vida temporal e da ação do Direito..., do Direito Legado em sua ação na História de Jesus na sua passagem entre nós, documentada pelas Escrituras, num aceite, que perdura nos estudos de exegetas de varias nações católicas e não católicas, sobre a revelação o princípio fundamental da exegese teológica. Temos esta fé arraigada e própria em cada homem ou mu-

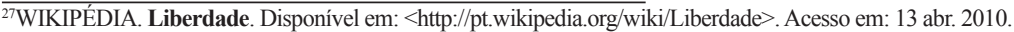

${ }^{28}$ RATZINGER, Joseph. Fé, Verdade, Tolerância: O cristianismo e as grandes religiões do mundo. Tradução Sivar Hoeppner Ferreira. Instituto Brasileiro de Filosofia e Ciência "Raimundo Lúlio" (Ramon Llull), 2007, p. 191.

${ }^{29}$ RATZINGER, Joseph. Fé, Verdade, Tolerância: O cristianismo e as grandes religiões do mundo. Tradução Sivar Hoeppner Ferreira. Instituto Brasileiro de Filosofia e Ciência "Raimundo Lúlio" (Ramon Llull), 2007, p. 209. 
lher em todos os tempos e a visão do Direito em todas as passagens bíblicas, um exemplo de proteção do que é certo e daquilo que não seria a palavra deixada por Deus. "Negar a passagem de Jesus pela terra seria hoje como assinar um atestado de obtusidade histórica ou se declarar descontextualizado com as novas descobertas." $" 30$

Também trouxe o artigo, uma transparência, ao conceito do filho do Deus vivo, apresentado pelos evangelistas e daquela partindo das Escrituras, que a Igreja de Roma apresenta como o Cristo da Fé.

Estes estudos, ao analisar, o Direito atribuído, no sentido de encontro com a Boa Fé Canônica enriqueceu o texto com uma simbiose interessante com a figura do Cardeal Joseph Ratzinger, "Filósofo do Direito" e agora "Papa Bento XVI" e a Boa Fé Canônica, com passagens interessantes, nos deixando bastante à vontade para o discernimento da palavra nas Escrituras do Direito Natural e da Fé.

A conotação que temos neste artigo, claramente o temor teofanico típico, o temor que invade o homem que se vê exposto imediatamente à presença de seus dogmas religiosos. Todas estas imagens desfilarão em suas reflexões, em uma variação talvez única, sem nenhuma pretenção maior, a não ser de trazer o conhecimento deixado em (Jô 10,10) em que "Jesus o filho de Deus Vivo veio para que o homem tenha vida e a tenha em abundância." ${ }^{1}$

Esta nova leitura esclarecerá em diversos e difíceis processos de distinção e de luta, assegurado pelos estudos e pesquisas nas bibliografias citadas, contra interpretações tanto mítico-politeístas, como as políticas e das divisões de credos.

Servimo-nos do exemplo do concílio de Nicéia (325 D.c.), para declarar nossa "Igual Essência" guardadas as devidas proporções e no preparo deste artigo, fruto da obediência e do temor a Deus.
7. Referências Bibliográficas

1. ARTIGAS, Mariano. Filosofia da natureza. Tradução José Eduardo de Oliveira e Silva. São Paulo, Instituto Brasileiro de Filosofia e Ciência "Raimundo Lúlio" (Ramon LLuLL), 2005 .

2. BÍBLIA SAGRADA. Tradução portuguesa da versão francesa dos originais, traduzidos pelos Monges Beneditinos de Maredsous (Bélgica). 178. ed. São Paulo: Ave Maria, 2008.

3. CASTRO, Flávia Lage. História do Direito Geral e Brasil. 6. ed. Rio de Janeiro: Lumen Juris, 2008.

4. Costa, Judith Martins. A Boa Fé no Direito Privado. São Paulo: Revista dos Tribunais, 2000.

5. GURGEL, Don Mario Teixeira. A Bíblia na Linguagem de Hoje. Rio de Janeiro: Sociedade Bíblica, 2003.

6. NADER, Paulo. Introdução ao Estudo do Direito. 28. ed. Rio de Janeiro: Editora Forense, 2007.

7. de Janeiro: Forense, 2006.

8. PRADO, Antônio Orlando de Almeida. Código de Hamurabi, Leis das XII Tábuas, Manual dos Inquisidores, Lei do Talião. São Paulo: Paulistanajur Ltda., 2004.

9. RAMPAZZO, Lino. Metodologia cientifica. 3. ed. São Paulo: Loyola, 2002.

10. RATZINGER, Joseph. Fé, Verdade, tolerância: $\mathrm{O}$ cristianismo e as grandes religiões do mundo. Tradução de Sivar Hoeppner Ferreira. São Paulo: Instituto Brasileiro de Filosofia e Ciência “Raimundo Lúlio" (Ramon Llull), 2007.

11. REALE, Miguel. Filosofia do Direito. 19. ed. São Paulo: Saraiva, 1999. 
12. SABADELL, Ana Lucia. Manual de sociologia jurídica: introdução a uma leitura externa do direito. 3. ed. São Paulo: Revista dos Tribunais, 2005.

13. SAlgado, Plínio. A Vida de Jesus Nazareno. São Paulo: Voz do Oeste, 1998.

14. SARANYANA, Josep-Ignasi. A Filosofia Medieval: das origens patrística à escolástica barroca. Tradução de Fernando Salles. São Paulo: Instituto Brasileiro de Filosofia Ciência "Raimundo Lúlio" (Ramon Llull), 2006.

15. SECCO, Orlando de Almeida. Introdução Ao Estudo do Direito. 10. ed. São Paulo: Lumen Juris, 2007.

16. LIMA, Elinaldo Renovato. As Bases Bíblicas da Unção. Disponível em: < http://www.assembleiadedeus-rn.org.br/ familia/port/estudos01.htm> Acesso em: 13 abr. 2010.

17. LÚCIA, Cláudia. Hermenêutica e Exegese: Princípios básicos. Disponível em: <http://claudialucia2007.blogspot. com/2007/11/hemenutica-exegeseprincpios-bsicos.html>. Acesso em: 13 abr. 2010 .

18. MARTINEZ, João Flávio. Manipulando o Jesus histórico. Disponível em: $<$ http://www. cacp.org.br/movimentos/artigo.aspx?lng=PT$\&$ article $=844 \&$ menu $=12 \&$ submenu $=3>$. Acesso em: 30 maio 2010.

19. SABINO, Mario. Bento XVI: A verdade, nada mais que a verdade. Disponível em: $<$ http://veja.abril.com.br/160507/p_070. shtml>. Acesso em: 30 maio 2010.

20. WIKIPÉDIA. Liberdade. Disponível em: $\quad<$ http://pt.wikipedia.org/wiki/ Liberdade>. Acesso em: 13 abr. 2010.

21. Tolerância.

Disponível em: $\quad<$ http://pt.wikipedia.org/wiki/ Toler $\%$ C3\%A2ncia $>$. Acesso em: 13 abr. 2010.

22. . Verdade. Disponível em: $<$ http:// pt.wikipedia.org/wiki/Verdade>. Acesso em: 13 abr. 2010.

\section{Endereço para Correspondência:}

Marcos Machado

marcos.machado@foa.org.br

Centro Universitário de Volta Redonda - UniFOA

Av. Paulo Erlei Alves Abrantes, no 1325

Três Poços, Volta Redonda - RJ

CEP 27240-560. 